\section{Ventilation-Perfusion Scanning: Stuck in a Rut, Perhaps, but the Road Ahead Is Not So Clear}

TO THE EDITOR: The recent editorial by Michael Graham extolled the virtues of ventilation-perfusion (V/Q) SPECT and its greater accuracy than either planar V/Q imaging or CT pulmonary angiography (CTPA) for detecting pulmonary emboli (PE) (1). I respect Dr. Graham's feeling on this matter but strongly disagree with his conclusions. This is a subject that I have dealt with for many years, and I have a very differing viewpoint from that offered by Dr. Graham.

The problem is that U.S. physicians practice defensive medicine worrying about lawyers looking over their shoulders. Any patient diagnosed with the smallest of PEs will be given anticoagulation treatment. I fully agree that SPECT is more accurate than planar imaging. However, in our country, that leads to overdiagnosis and overtreatment, with the potential for $8 \%-10 \%$ complications associated with blood thinners. We must, therefore, avoid diagnosing on CTPA or V/Q SPECT these small PEs that many authors have shown should not be treated (2-4). Dr. Lawrence Goodman, a chest radiologist from Milwaukee, points out that the only reasons to treat small PEs are coexistent deep venous thrombosis, inadequate cardiopulmonary reserve, and chronic PE (5). He even mentions that there is good evidence that healthy people often pass small clots from the legs to the lungs every day and that the lung capillary bed traps the emboli, protecting the systemic circulation. So-in the United States, PE is a problem that should be handled by outcomes rather than the accuracy medicine that Dr. Graham is advocating. Of course, V/Q SPECT is more accurate, but it works to the detriment of the patient for small PEs that are unnecessarily treated in the United States.

At New York's Montefiore Medical Center, we perform more than 3,500 planar V/Q studies a year. In addition, for the past $5 \mathrm{y}$ we have used a more understandable trinary interpretive algorithm in place of the older probability interpretations. Outcomes, based on 3-mo follow-ups, have shown comparable results for both interpretations, with a false-negative rate of $1 \%-1.5 \%$ (6). More recently, we had the opportunity to review follow-up outcomes data on more than 3,000 planar V/Q studies and 1,800 CTPA studies. The outcomes for both procedures are essentially the same, at $1 \%-$ $1.5 \%$. The well-known multiinstitutional prospective study of Anderson et al. in Canada showed greater sensitivity for CTPA ( $17.7 \%$ vs. $11.7 \%$ for planar V/Q) but comparable outcomes of approximately $1 \%$ (7). Another outcomes study for V/Q SPECT had a similar $1.5 \%$ false-negative rate $(8)$. These studies clearly indicate that the smaller clots picked up on CTPA or V/Q SPECT do not need to be treated. They justify the continued use of planar $\mathrm{V} / \mathrm{Q}$, particularly in the United States.

Most importantly, there is an ongoing multiinstitutional study (NCT01455818, clinicaltrials.gov) centered in Ottawa headed by Drs. Philip Wells and Gregoire Le Gal that is randomizing treatment versus nontreatment for small PEs. Early results suggest no difference. If these results continue, U.S. physicians may be con-

COPYRIGHT (c) 2014 by the Society of Nuclear Medicine and Molecular Imaging, Inc. vinced to trust their clinical judgment and not treat uncomplicated small PEs. When that day arrives, I would certainly consider using the more sensitive SPECT for selective V/Q studies.

\section{REFERENCES}

1. Graham MM. Ventilation-perfusion lung imaging: stuck in a rut? J Nucl Med. 2014;55:1395-1396.

2. Wiener RS, Schwartz LM, Woloshin W. When a test is too good: how CT pulmonary angiograms find pulmonary emboli that do not need to be found. BMJ. 2013;347:f3368.

3. Suh JM, Cronan JJ, Healey TT. Dots are not clots; the over-diagnosis and overtreatment of PE. Emerg Radiol. 2010;17:347-352.

4. Sheh SH, Bellin E, Freeman KD, Haramati LB. Pulmonary embolism diagnosis and mortality with pulmonary CT angiography versus ventilation-perfusion scintigraphy: evidence of overdiagnosis with CT? AJR. 2012;198:1340-1345.

5. Goodman LR. Small pulmonary emboli: what do we know? Radiology. 2005;234: 654-658.

6. Glaser JE, Chamarthy M, Haramati LB, Esses D, Freeman LM. Successful and safe implementation of a trinary interpretation and reporting strategy for V/Q lung scintigraphy. J Nucl Med. 2011;52:1508-1512.

7. Anderson DR, Kahn SR, Rodger MA, et al. Computed tomographic pulmonary angiography vs. ventilation-perfusion lung scanning in patients with suspected pulmonary embolism: a randomized controlled trial. JAMA. 2007;298:2743-2753.

8. Leblanc M, Leveillée F, Turcotte E. Prospective evaluation of the negative predictive value of V/Q SPECT using ${ }^{99 m}$ Tc-Technegas. Nucl Med Commun. 2007;28:667-672.

Leonard M. Freeman

Montefiore Medical Center

111 E. 210th St.

Bronx, New York 10022

E-mail: Ifreeman@montefiore.org

Published online Nov. 7, 2014.

DOI: $10.2967 /$ jnumed.114.148148

TO THE EDITOR: The recent editorial by Michael Graham states that the reason ventilation-perfusion (V/Q) SPECT has been slow to be adopted in the United States is due to confusion about the approach to interpretation of the studies; however, he states that the issue has been resolved-that is, follow the European procedure guidelines, eliminate probability categories, and interpret the studies as the presence or absence of pulmonary embolism (1). Some of the data supporting these statements deserve further discussion. However, this letter will focus on one particular aspect, the ventilation agent used for SPECT. To support the thesis that SPECT should be standard, the editorial specifically references one prospective and two retrospective publications supporting the use of SPECT $(2-4)$. The ventilation agents used in the first two were ${ }^{81 \mathrm{~m}} \mathrm{Kr}$ and ${ }^{99} \mathrm{~m}$ Tc-Technegas (Cyclomedica Ltd.). Both are excellent ventilation agents; however, neither is available in the United States. The third publication did not use ${ }^{99 \mathrm{~m}} \mathrm{Tc}$-diethylenetriaminepentaacetic acid (DTPA) as stated in the editorial but rather evaluated ${ }^{99 \mathrm{~m}}$ Tc-macroaggregated albumin SPECT without a ventilation scan.

${ }^{133} \mathrm{Xe}$ and ${ }^{99 \mathrm{~m}} \mathrm{Tc}$-DTPA are by far the most commonly used radiopharmaceuticals for ventilation studies in the United States. Most imaging clinics use ${ }^{99 \mathrm{~m}} \mathrm{Tc}$-DTPA because it produces good image quality, can obtain multiple views that match perfusion 